\title{
Vitamin C inhibits p53-induced replicative senescence through suppression of ROS production and p38 MAPK activity
}

\author{
JEE-EUN KIM ${ }^{1,2 *}$, DONG-HOON JIN ${ }^{1,2 *}$, SOON-DUCK LEE ${ }^{3}$, SEUNG-WOO HONG ${ }^{1,2}$, JAE-SIK SHIN ${ }^{1,2}$, \\ SEUNG-KOO LEE ${ }^{1}$, DA-JUNG JUNG ${ }^{1,2}$, JAE-SEUNG KANG ${ }^{1}$ and WANG-JAE LEE ${ }^{1,2}$ \\ ${ }^{1}$ Departments of Anatomy and Tumor Immunity Medical Research Center, ${ }^{2}$ Cancer Research Institute, \\ Seoul National University College of Medicine, Jongno-Gu, Seoul; ${ }^{3}$ Research Center for Women's Diseases, \\ Division of Biological Sciences, Sookmyung Women's University, Seoul, Korea
}

Received April 29, 2008; Accepted July 4, 2008

DOI: 10.3892/ijmm_00000068

\begin{abstract}
We previously reported that tumor cells expressing p53 increase intracellular levels of reactive oxygen species (ROS). In this study, we described an inhibitory effect of vitamin $\mathrm{C}$ on replicative senescence. Vitamin $\mathrm{C}$ was found to inhibit p53-induced senescence in human bladder cancer EJ cells. The senescence-like phenotype (SLP) induced by p53, which showed a morphological change and an irreversible cell cycle arrest, was not observed in vitamin C-treated EJ cells. In addition, vitamin $\mathrm{C}$ did not significantly affect normal cell proliferation. We investigated the molecular mechanisms of the inhibitory effect of vitamin $\mathrm{C}$ on the development of replicative senescence in EJ cells. We found that vitamin $\mathrm{C}$ inhibited this p53-induced ROS generation. Moreover, p38 kinase which was activated during p53-induced senescence was not observed in vitamin C-treated EJ cells. SB203580, a chemical inhibitor of p38 kinase, was found to consistently inhibit p53-induced senescence. Therefore, it is suggested that vitamin $\mathrm{C}$ inhibits p53-induced senescence by preventing ROS generation, which in turn leads to the activation of $\mathrm{p} 38$ MAPKinase. These results reveal the inhibitory mechanism of vitamin $\mathrm{C}$ on cellular senescence.
\end{abstract}

\section{Introduction}

Vitamin $\mathrm{C}$ acts as an antioxidant in mammalian cells. The majority of previous studies have reported that vitamin $\mathrm{C}$ protects cells from oxidative stress, which can induce cancer

Correspondence to: Dr Wang-Jae Lee, Department of Anatomy and Tumor Immunity Medical Research Center, Seoul National University College of Medicine, Seoul 110-744, Korea

E-mail: kinglee@snu.ac.kr

${ }^{*}$ Contributed equally

Key words: Vitamin C, p53, reactive oxygen species, p38 mitogen activated protein kinase and aging via DNA damage (1-3). However, the molecular mechanisms of vitamin $\mathrm{C}$ cellular senescence have not been fully elucidated.

Senescent cells display characteristic phenotypic markers, such as an enlarged and flattened morphology, irreversible growth arrest and the expression of senescence-associated $\beta$-galactosidase (SA-B-Gal) activity at pH 6.0 (4). It has been demonstrated that the expression of ras and raf oncogenes can induce a rapid onset of replicative senescence in normal fibroblast cells and that this is associated with the induction of p53, p21, p16 and p19, and the hypophosphorylation of Rb protein (5-7). This implies that replicative senescence, such as apoptosis, is a programmed response of an organism to a potentially oncogenic impact.

Several studies have shown that oxidants are important factors for the induction of cellular senescence. Studies with human diploid fibroblasts have demonstrated that cells treated with hydroperoxide $\left(\mathrm{H}_{2} \mathrm{O}_{2}\right)$ reveal a shortened telomere length per population doubling (8) and induce cellular senescence (9-11). The role of oxidants in cellular senescence has been further understood by observations demonstrating that tumor cells expressing tumor suppressor genes, such as p53 and p21, increase the intracellular ROS levels $(6,12)$. Antioxidants consistently inhibit the induction of senescence phenotypes (12). Thus, ROS is essential for the induction of senescence phenotypes in cells expressing p53 or p21.

In this study, we investigated the effects of vitamin $\mathrm{C}$ on p53-induced replicative senescence. ROS levels are increased by overexpression of p53 in the p53-negative cancer cell line EJ and subsequent activation of p38 mitogen activated protein kinase (MAPK). Thus, we used the ROS-mediated senescence system to examine whether vitamin $\mathrm{C}$ inhibits replicative senescence through the blockage of ROS induction or other responses.

\section{Materials and methods}

Cell cultures, recombinant adenovirus and materials. Human bladder cancer EJ cells, were maintained in DMEM supplemented with 10\% FBS (Life Technologies, Inc., Grand Island, $\mathrm{NY})$ and penicillin-streptomycin $(50 \mathrm{U} / \mathrm{ml})$. Recombinant adenoviruses encoding wild-type p53 were purchased from 
Vector BioLabs (Philadelphia, PA). Vitamin C and tert-butylhydrogen peroxide (t-BTH) were purchased from Sigma Chemical Company (Sigma, St. Louis, MO).

Senescence-associated $\beta$-galactosidase (SA-B-Gal) analysis. Cells were washed in PBS and fixed in a solution of $0.25 \%$ glutaraldehyde in $\mathrm{PBS}$, and $2 \mathrm{mM} \mathrm{MgCl}_{2}$ was added at room temperature for $20 \mathrm{~min}$. SA- $3-\mathrm{Gal}$ activity at $\mathrm{pH} 6.0$ was detected as previously described (12).

Measurement of ROS levels. Cells were incubated with $10 \mu \mathrm{M}$ $\mathrm{H}_{2}$ DCF-DA (Molecular Probes, Carlsbad, CA) for $30 \mathrm{~min}$, washed with PBS, trypsinized and collected in $1 \mathrm{ml}$ of PBS. Fluorescence-stained cells were transferred to polystyrene tubes with cell-strainer caps (BD Biosciences, San Jose, CA) and sorted using a fluorescence-activated cell sorter (FACScalibur $^{\mathrm{TM}}$, BD Biosciences). Cell Quest 3.2 software (Becton Dickinson, NJ, USA) was used for analysis (12).

Immunoblot analysis. Cell lysates were prepared by lysis in RIPA buffer (50 mM Tris- $\mathrm{HCl}, \mathrm{pH} 7.5,50 \mathrm{mM} \mathrm{NaCl}, 1 \mu \mathrm{M}$ EGTA, $1 \%$ Triton X-100, $50 \mathrm{mM} \mathrm{NaF}, 5 \mathrm{mM} \mathrm{Na}_{3} \mathrm{VO}_{4}, 10 \mathrm{mM}$ $\mathrm{Na}_{4} \mathrm{P}_{2} \mathrm{O}_{7}, 0.1 \mathrm{mM}$ phenylmethylsulfonyl fluoride, $1 \mu \mathrm{g} / \mathrm{ml}$ aprotinin, $1 \mu \mathrm{g} / \mathrm{ml}$ pepstatin $\mathrm{A}, 1 \mu \mathrm{g} / \mathrm{ml}$ leupeptin and $1 \mathrm{mM}$ DTT). Extracts normalized for protein concentrations using the Bradford assay, and $20 \mu \mathrm{g}$ of total cell protein per sample were subjected to sodium dodecyl sulfate-polyacrylamide gel electrophoresis (SDS-PAGE) and then transferred to a PolyScreen membrane (Nen, Boston, MA). Membranes were incubated in a solution of 5\% nonfat dry milk in TBST buffer (20 mM Tris- $\mathrm{HCl}, \mathrm{pH} 7.4,150 \mathrm{mM} \mathrm{NaCl}$ and $0.1 \%$ Tween-20) and probed with one of the following antibodies: p-p38 (Cell Signaling Technology, Beverley, MA) p38, p53, Hdm2/Mdm2 and tubulin (Santa Cruz Biotechnology, Santa Cruz, CA). The primary antibodies were detected with either goat anti-mouse or goat anti-rabbit, horseradish peroxidase-conjugated secondary antibodies, followed by enhanced chemiluminescence (Amersham, Buckinghamshire, UK).

\section{Results}

Vitamin C inhibits p53-induced replicative senescence. Since vitamin $C$ has been shown to affect various cell functions such as cell growth and apoptosis, we first examined the effects of vitamin $\mathrm{C}$ on cell proliferation before analyzing its effects on senescence (Fig. 1A). Dead cells were not found in EJ cells treated with 0.15 or $0.3 \mathrm{mM}$ vitamin $\mathrm{C}$, but they were found in cells treated with 0.5 or $1 \mathrm{mM}$. Therefore, low doses $(0.15$ and $0.3 \mathrm{mM}$ ) of vitamin $\mathrm{C}$ did not affect normal cell proliferation, but high doses $(0.5$ and $1 \mathrm{mM})$ induced cell death regardless of the growth stage (Fig.1A).

To determine whether a low dose $(0.15 \mathrm{mM})$ of vitamin $\mathrm{C}$ inhibits senescence phenotypes, we first examined the effect of vitamin $\mathrm{C}$ on the proliferation of cells infected with $\mathrm{p} 53$ adenovirus. The cells were treated with $0.15 \mathrm{mM}$ vitamin $\mathrm{C}$ after infection with p53-adenovirus, and the total number of cells was counted (Fig. 1B). Growth of the cells treated with vitamin $\mathrm{C}$ was not affected by p53-adenovirus and was similar to that of normally proliferating cells (Fig. 1B). We then examined SA-B-Gal activity and morphological characteristics
A

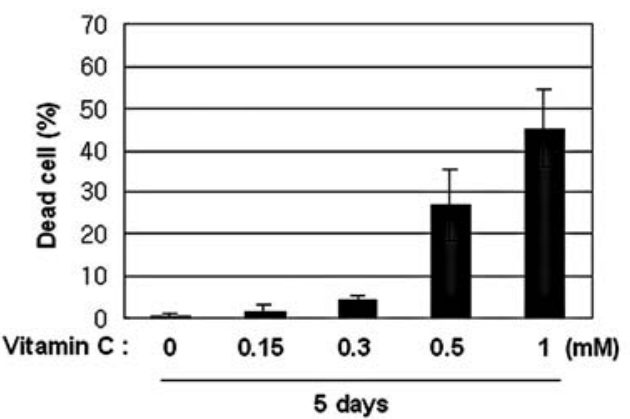

B

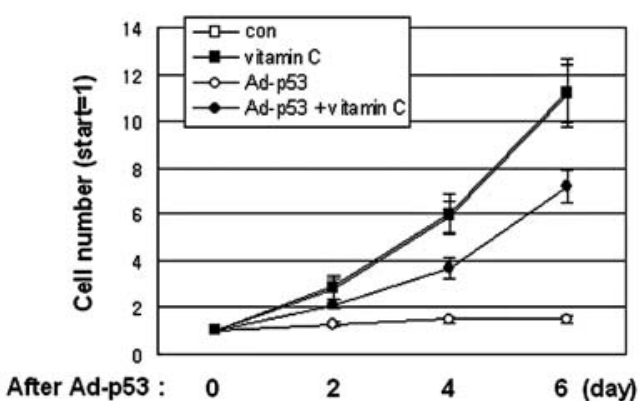

Figure 1. The effects of vitamin $\mathrm{C}$ on cell proliferation. (A) Normally growing EJ cells were treated with $0.15,0.3,0.5$ and $1 \mathrm{mM}$ vitamin $\mathrm{C}$, and the number of cells was counted 5 days later. Cell death was determined by counting tryphan blue-stained cells. (B) Normally growing EJ cells and p53expressing EJ cells were treated with $0.15 \mathrm{mM}$ vitamin $\mathrm{C}(\boldsymbol{\square}, \bullet)$ or were left untreated $(\square, \odot)$, and the number of cells was counted at the indicated time points. Each point represents the average of 3 independent experiments.

of the cells treated with vitamin $\mathrm{C}$ in comparison with controls and cells infected with p53-adenovirus (Fig. 2A and B). Consistent with SA- $\beta-$ Gal activity, the morphological characteristics of senescent cells were significantly reduced in the cells infected with p53-adenovirus following the treatment of vitamin $\mathrm{C}$ without induction of cell death. Notably, vitamin $\mathrm{C}$ decreased the protein level of p53 which was expressed by infection with p53-adenovirus of p53-negative EJ cells (Fig. 2C). SA-B-Gal activity was also decreased by $0.3 \mathrm{mM}$ vitamin $\mathrm{C}$ in the cells infected with p53-adenovirus. However, $0.15 \mathrm{mM}$ vitamin $\mathrm{C}$ produced a greater decrease than $0.3 \mathrm{mM}$. Unlike the effects of $0.3 \mathrm{mM}$ vitamin $\mathrm{C}$ alone on cell proliferation, dead cells were observed in the cells infected with p53-adenovirus following treatment of $0.3 \mathrm{mM}$ vitamin $C$ (data not shown). These results indicate that vitamin $C$ inhibits replicative senescence induced by p53 in the p53-deficient cell line, EJ.

Vitamin $C$ inhibits an increase in ROS levels by p53. It has been reported that tumor suppressor genes, such as p53 and p21, increase intracellular reactive oxygen species (ROS) levels, which play a key role in senescence (12-14) and in vivo aging (15-17). Thus, an increased ROS level by p53 is important for the induction of senescence. We, therefore, investigated whether vitamin $\mathrm{C}$ affected ROS production by p53 (Fig. 3). ROS levels in EJ cells expressing p53 were found to significantly decrease one day after vitamin $\mathrm{C}$ treatment (Fig. 3B and C). In addition, ROS levels in control EJ cells were also found to decrease after vitamin $C$ treatment 
A

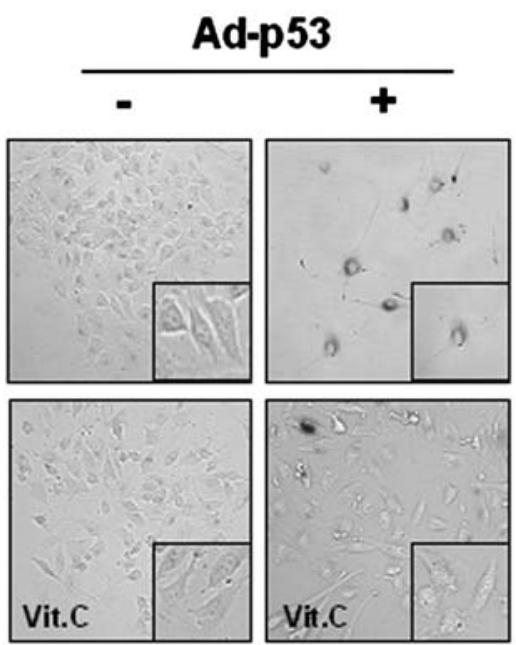

$\mathbf{C}$

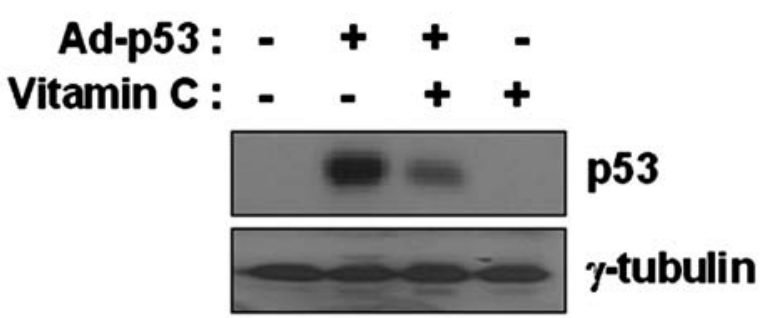

B

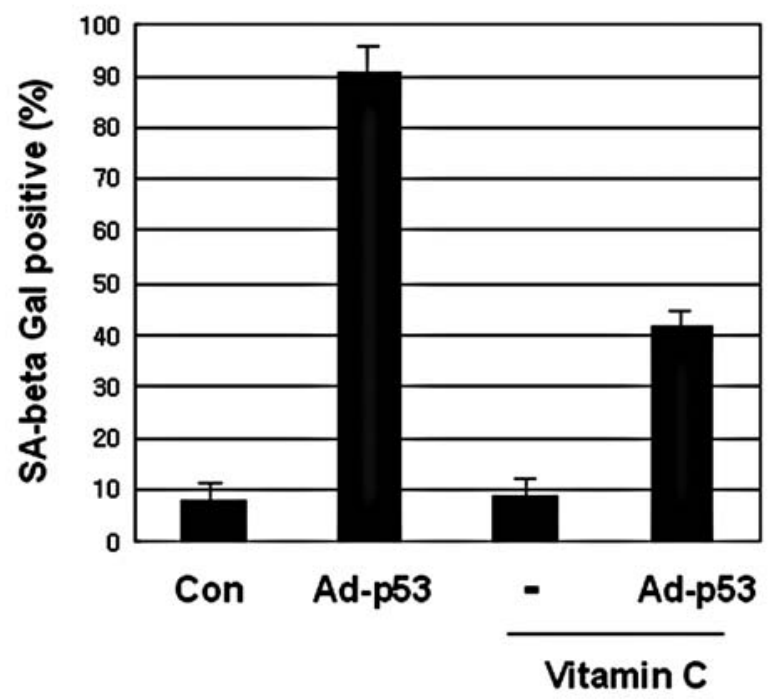

Figure 2. Vitamin C inhibits senescence phenotypes induced by p53. (A) Cells were treated with $0.15 \mathrm{mM}$ vitamin $\mathrm{C} 2 \mathrm{~h}$ after infection with p53-adenovirus, and SA- $\beta-$ Gal activity was analyzed. The results represent the mean \pm SD of 3 independent experiments. (B) SA- $\beta-$ Gal staining 5 days after the infection with p53-adenovirus following vitamin $\mathrm{C}$ treatment. (C) Expression of p53 protein in EJ cells was analyzed by immunoblotting.

A
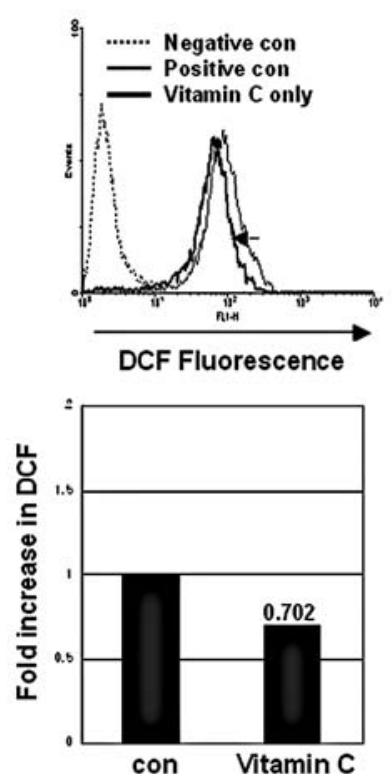

B
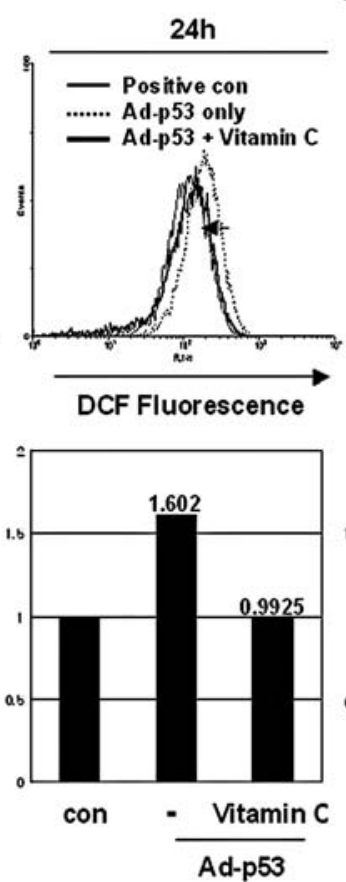

c
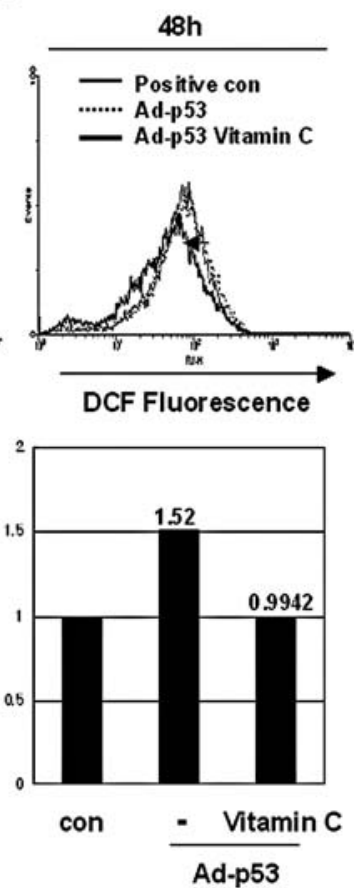

Figure 3. Vitamin C inhibits ROS generation by p53. (A) Normally growing EJ cells and p53-infected EJ cells were treated with 0.15 mM vitamin C or were left untreated, and were cultured for $24 \mathrm{~h} \mathrm{(B),} 48 \mathrm{~h}(\mathrm{C})$ and $3 \times 10^{5}$ cells were subjected to FACS analysis after staining with DCF, a fluorescent probe. Each point represents the average of 3 independent experiments. 


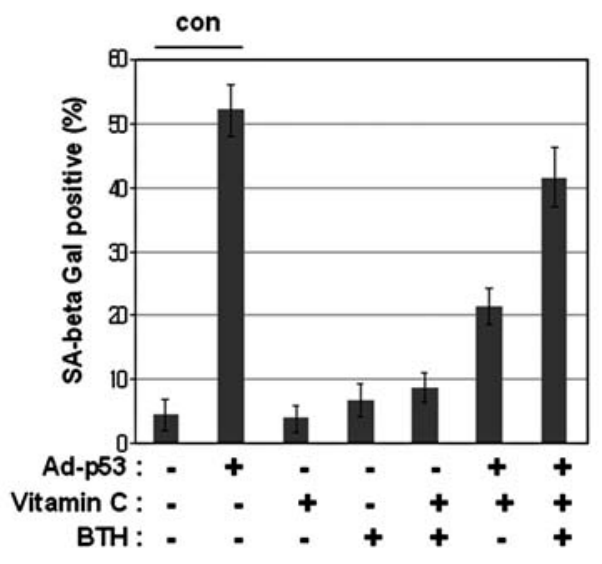

Figure 4. Senescence phenotypes inhibited by vitamin $\mathrm{C}$ were overridden by pro-oxidant, t-BTH. p53-infected EJ cells treated with vitamin $\mathrm{C}$ were cultured with $10 \mu \mathrm{M}$ t-BTH for 5 days, and SA- $\beta$-Gal activity was analyzed. The data represent the mean $\pm \mathrm{SD}$ of 3 independent experiments.

(Fig. 3A), showing that vitamin $\mathrm{C}$ prevents ROS generation by p53 in EJ cells.

To support the aforementioned results, we aimed to confirm whether senescence phenotypes inhibited by vitamin $\mathrm{C}$ are recovered by pro-oxidants such as tert-butyl$\mathrm{H}_{2} \mathrm{O}_{2}$ (t-BTH). We post-treated p53-expressing EJ cells with t-BTH after vitamin $C$ treatment. SA- 3 -gal activity was significantly increased after t-BTH addition in p53-expressing cells treated with vitamin $\mathrm{C}$ (Fig. 4). These results suggest that the inhibitory effect of vitamin $\mathrm{C}$ on p53-induced ROS production was offset after t-BTH treatment in EJ cells.
Vitamin $C$ inhibits the activity of p38 kinase induced by $p 53$. MAPK can promote growth arrest, replicative senescence and apoptosis when cells are exposed to different apoptotic stimuli. A previous study reported that p38 kinase is activated during p53-induced senescence (12). Based on this study, we examined whether vitamin $C$ inhibits the activity of p38 kinase induced by p53 in EJ cells. The phosphorylation of p38 kinase induced by $\mathrm{p} 53$ was dramatically suppressed by vitamin $\mathrm{C}$ (Fig. 5A). In addition, the inhibitory effect of vitamin $\mathrm{C}$ on senescence phenotypes was almost the same as that of SB203580, a specific chemical inhibitor of p38 kinase (Fig. 5B). These results suggest that vitamin $C$ inhibits senescence phenotype through suppression of p38 kinase activity induced by p53 in EJ cells.

\section{Discussion}

In this study, we investigated the effects of vitamin $\mathrm{C}$ on cellular senescence. Although it has been suggested that vitamin $C$ has an anti-aging effect $(18,19)$, its molecular mechanism is unclear. Based on the results of our previous study suggesting that $\mathrm{Bcl}-\mathrm{xL}$ and $\mathrm{E} 1 \mathrm{~B}-19 \mathrm{~K}$ prevent ROS production by $\mathrm{p} 53$ and subsequently inhibit cellular senescence (12), we focused on the inhibitory mechanisms of vitamin C on cellular senescence by using this experimental method. We found that vitamin $\mathrm{C}$ inhibited p53-induced senescence through blockage of the ROS-p38 kinase pathway.

Treatment with a low dose of vitamin $\mathrm{C}$, which did not affect cell death, inhibited senescence phenotypes induced by p53 in EJ cells (Figs. 1 and 2). In addition, the expression of exogenous p53 protein was decreased after vitamin $\mathrm{C}$ treatment (Fig. 2C). We, therefore, aimed to confirm whether
A

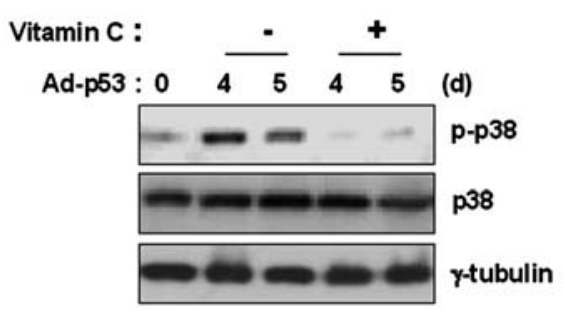

B

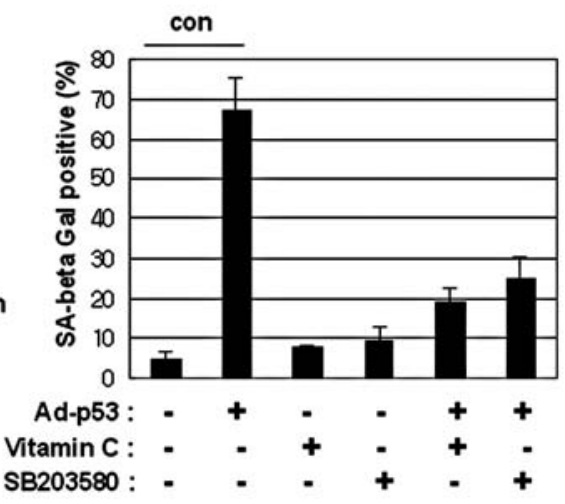

Figure 5. Vitamin C inhibits the activity of p38 kinase in p53-induced senescence. (A) Immunoblot analysis of phosphorylated p38 kinase at the indicated time points after EJ cells infected with adenovirus p53 were treated with $0.15 \mathrm{mM}$ vitamin $\mathrm{C}$. (B) A comparison of vitamin $\mathrm{C}$ and $\mathrm{t}-\mathrm{BTH}$ in terms of the inhibitory effects of senescence phenotypes induced by p53. EJ cells infected with p53-adenovirus were treated with either vitamin C (0.15 mM) or SB203580 $(10 \mu \mathrm{M})$. The number of SA- $\beta$-Gal-positive cells was counted 5 days later. The results represent the mean \pm SD of 3 independent experiments.

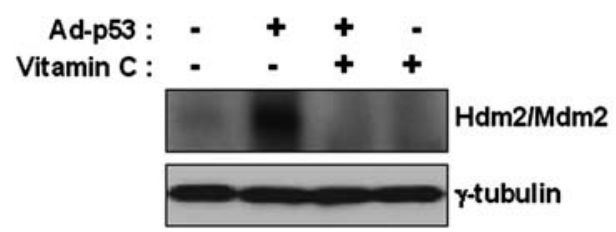

Figure 6. The effect of vitamin $\mathrm{C}$ on Hdm2 expression. p53-infected EJ cells were treated with $0.15 \mathrm{mM}$ vitamin $\mathrm{C}$ or were left untreated, and immunoblotting was performed as shown in Fig. 2C. 
the decreased p53 was related to the expression of $\mathrm{Hdm} 2 / \mathrm{mdm} 2$, which directly binds to and degrades it (Fig. 6). However, our data showed that the expression of exogenous p53 protein was regulated independently of $\mathrm{Hdm} 2 / \mathrm{mdm} 2$, indicating that vitamin $\mathrm{C}$ can down-regulate the expression of p53 via other E3 ligases. Thus, these results demonstrate that vitamin $\mathrm{C}$ suppresses p53 expression and subsequently inhibits senescence phenotypes. Further studies are required to confirm the inhibitory mechanism of $\mathrm{p} 53$ by vitamin $\mathrm{C}$ in $\mathrm{p} 53$ induced senescence.

Numerous studies have reported that vitamin $\mathrm{C}$ functions as an antioxidant (21). We previously reported that ROS induction by p53 is essential for senescence induction (12), and thus we aimed to confirm whether vitamin $\mathrm{C}$ regulates ROS generation. ROS induced by p53 was significantly reduced by vitamin $\mathrm{C}$ (Fig. 3). This was further supported by the finding that the inhibition of senescence phenotypes by vitamin C was overcome by exogenous ROS (Fig. 4). To elucidate the molecular mechanisms by which vitamin $C$ inhibits p53-induced senescence, we then focused on the effect of vitamin $\mathrm{C}$ on the activity of $\mathrm{p} 38$ kinase. We reported that p38 kinase is activated during p53-induced senescence and its phosphorylation is paralleled by ROS induction (12). Collectively, our results confirm that vitamin $\mathrm{C}$ blocks the phosphorylation of p38 kinase in p53-induced senescence (Fig. 5). The activation of p38 kinase, after infection with adenovirus $\mathrm{p} 53$, was blocked by vitamin $\mathrm{C}$. The results of this study suggest that vitamin $\mathrm{C}$ may have a novel function in its involvement with the inhibition of p53-induced senescence.

\section{Acknowledgements}

This work was supported by grant no. 800-20050059 from the Basic Research Program of the Korea Science and Engineering Foundation through the Tumor Immunity Medical Research Center at Seoul National University College of Medicine, R13-2002-025-02001-0, and through the Research Center for Women's Disease of the KOSEF, R11-2005-017-03001, at Sookmyung Women's University.

\section{References}

1. Scharffetter-Kochanek K, Wlaschek M, Brenneisen P, Schauen M, Blaudschun $\mathrm{R}$ and Wenk $\mathrm{J}$ : UV-induced reactive oxygen species in photocarcinogenesis and photoaging. Biol Chem 378: 1247-1257, 1997.

2. Squire TC: Oxidative stress and protein aggregation during biological aging. Exp Gerontol 36: 1539-1550, 2001.

3. Burhans WC and Weinberger M: DNA replication stress, genome instability and aging. Nucleic Acids Res 35: 7545-7556, 2007.

4. Dimri GP, Lee X, Basile G, Acosta M, Scott G, Roskelley C, Medrano EE, Linskens M, Rubelj I and Pereira-Smith O: A biomarker that identifies senescent human cells in culture and in aging skin in vivo. Proc Natl Acad Sci USA 92: 9363-9367, 1995.
5. Serrano M, Lin AW, McCurrach ME, Beach D and Lowe SW: Oncogenic ras provokes premature cell senescence associated with accumulation of p53 and p16INK4a. Cell 88: 593-602, 1997.

6. Macip S, Igarashi M, Fang L, Chen A, Pan ZQ, Lee SW and Aaronson SA: Inhibition of p21-mediated ROS accumulation can rescue p21-induced senescence. EMBO J 21: 2180-2188, 2002.

7. Macip S, Igarashi M, Berggren P, Yu J, Lee SW and Asronson SA: Influence of induced reactive oxygen species in p53-mediated cell fate decisions. Mol Cell Biol 23: 8576-8585, 2003.

8. Von Zglinicki T, Saretzki G, Döcke W and Lotze C: Mild hyperoxia shortens telomeres and inhibits proliferation of fibroblasts: a model for senescence? Exp Cell Res 220: 186-193, 1995.

9. Chen QM, Bartholomew JC, Campisi J, Acosta M, Reagan JD and Ames BN: Molecular analysis of $\mathrm{H}_{2} \mathrm{O}_{2}$-induced senescentlike growth arrest in normal human fibroblasts: p53 and Rb control G1 arrest but not cell replication. Biochem J 332: 43-50, 1998.

10. Frippiat C, Dewelle J, Remacle J and Toussaint O: Signal transduction in $\mathrm{H}_{2} \mathrm{O}_{2}$-induced senescence-like phenotype in human diploid fibroblasts. Free Radic Biol Med 33: 1334-1346, 2002.

11. Zdanov S, Remacle J and Toussaint O: Establishment of $\mathrm{H}_{2} \mathrm{O}_{2-}$ induced premature senescence in human fibroblasts concomitant with increased cellular production of $\mathrm{H}_{2} \mathrm{O}_{2}$. Ann NY Acad Sci 1067: 210-216, 2006.

12. Jung MS, Jin DH, Chae HD, Kang S, Kim SC, Bang YJ, Choi TS, Choi KS and Shin DY: Bcl-xL and E1B-19K proteins inhibit p53-induced irreversible growth arrest and senescence by preventing reactive oxygen species-dependent p38 activation. J Biol Chem 279: 17765-17771, 2004.

13. Packer L and Smith JR: Extension of the lifespan of cultured normal human diploid cells by vitamin E: a re-evaluation. Proc Natl Acad Sci USA 74: 1640-1641, 1977.

14. Lee AC, Fenster BE, Ito H, Takeda K, Bae NS, Hirai T, Yu ZX, Ferrans VJ, Howard BH and Finkel T: Ras proteins induce senescence by altering the intracellular levels of reactive oxygen species. J Biol Chem 274: 7936-7940, 1999.

15. Hagen TM, Yowe DL, Bartholomew JC, Wehr CM, Do KL, Park JY and Ames BN: Mitochondrial decay in hepatocytes from old rats: membrane potential declines, heterogeneity and oxidants increase. Proc Natl Acad Sci USA 94: 3064-3069, 1997.

16. Harman D: Aging: a theory based on free radical and radiation chemistry. J Gerontol 11: 298-300, 1956.

17. Sohal RS and Weindruch R: Oxidative stress, caloric restriction, and aging. Review. Science 273: 59-63, 1996.

18. Sharma P, Rupar CA and Rip JW: Consequences of aging on mitochondrial respiratory chain enzymes in cultured human fibroblasts treated with ascorbate. Gerontology 44: 78-84, 1998.

19. Lykkesfeldt J, Hagen TM, Vinarsky V and Ames BN: Ageassociated decline in ascorbic acid concentration, recycling, and biosynthesis in rat hepatocytes reversal with (R)- $\alpha$-lipoic acid supplementation. FASEB J 12: 1183-1189, 1998.

20. Lai Z, Yang T, Kim YB, Sielecki TM, Diamond MA, Strack P, Rolfe M, Caligiuri M, Benfield PA, Auger KR and Copeland RA Differentiation of Hdm2-mediated p53 ubiquitination and Hdm2 autoubiquitination activity by small molecular weight inhibitors. Proc Natl Acad Sci USA 99: 14734-14739, 2002.

21. Reiter RJ: Oxidative processes and antioxidative defense mechanisms in the aging brain. FASEB J 9: 526-533, 1995. 